Substance Misuse in Personality Disorder and Schizophrenia: Findings and clinical implications from a high secure hospital

\begin{tabular}{|r|l|}
\hline Journal: & Journal of Forensic Practice \\
\hline Manuscript ID & JFP-07-2016-0035.R2 \\
\hline Manuscript Type: & Research Paper \\
\hline Keywords: & $\begin{array}{l}\text { substance misuse, mental illness, personality disorder, schizophrenia, } \\
\text { Treatment needs, violence, offending behaviour }\end{array}$ \\
\hline \multicolumn{2}{|l}{} \\
\hline
\end{tabular}




\title{
Substance Misuse in Personality Disorder and Schizophrenia: Findings and clinical implications from a high secure hospital
}

\begin{abstract}
Purpose - Substance misuse is widely prevalent in mentally disordered offenders and is linked with violence and offending behaviour. There is however, a scarcity of literature dedicated to investigating substance misuse and its clinical correlates in relation to patients detained within high secure hospital settings. This paper aims to investigate the extent and severity of substance misuse (SMU) and corresponding treatment needs in patients with a primary diagnosis of personality disorder (PD) in comparison with mental illness (MI) in a high secure hospital.

Design/methodology/approach - The Responsible Clinicians (RC) of all patients $(n=240)$ detained in a high secure hospital were asked to record information using a Substance Misuse Screening Questionnaire over a 10 month period. Details requested included substance type, history of past use and assessment and treatment needs. Data was recorded and then analysed: descriptive statistics were conducted to report historical use of substances, cross tabulations and chi square analysis explored the relationship between SMU and treatment status and diagnosis and offending behaviour and a means comparison analysis was employed to explore length of stay and treatment of SMU.

Findings - A total of 230 questionnaires were returned (95\% of the patient population). A history of SMU was reported in $88.6 \%$ of the sample, with alcohol and cannabis misuse being the most prevalent. At least one substance had been abused by $74.3 \%$ of the sample. In two thirds of the sample, SMU was linked with the onset of mental health problems and symptom exacerbation, including violence. Interestingly, patients with a diagnosis of $\mathrm{MI}$ as compared with PD were more likely to have used substances (93.3\% compared to $81.9 \%$ ) and were more likely to need treatment for SMU (64.3\% compared to 36.8\%). In those with an MI diagnosis, SMU was more likely to be linked with violence and index offence (74.3\% compared to 59.0\%).

Originality/value - This study substantiates existing evidence that SMU contributes to mental health problems and criminogenic behaviour. Furthermore, the study reports new findings that characterize differences of the relationship of substance misuse to offending in schizophrenia and personality disorder in forensic psychiatric patients presenting to a high secure hospital.
\end{abstract}


Keywords - Substance Misuse, Mental Illness, Personality Disorder, Treatment needs, Violence, Offending behaviour

Paper Type-Research paper

Word count (excluding abstract) $=4986$

Tables $=4$

Figures $=0$ 


\section{Introduction}

Previous evidence has demonstrated that the rate of Substance Misuse (SMU) within the psychiatric population is considerably higher than within a general population (D'Silva and Ferriter, 2003; Farrell et al., 1998). For forensic psychiatric patients, statistics are often even higher, with rates among patients admitted to forensic units typically between $50 \%$ and $90 \%$ (Derry, 2008). There is no clear agreement with regards to the link between mental disorder and violence; the link between a particular diagnosis and violence has been defined as "controversial and emotive" by some authors (Fazel et al., 2009). A variety of studies indicate that there is an association between serious violence and Schizophrenia, and that this link could be explained simply on the basis of either comorbid substance abuse, or prior criminal offending (Bennett et al., 2011; Fazel et al., 2009). In addition, many studies have attested an association between violence and psychopathic traits (Serin, 1991). Thus, the relationship between violence, mental disorders and substance misuse has been widely documented (Johnson et al., 2014; Steadman et al., 1998).

In contrast, some studies have suggested that rather than clinical factors, criminogenic risk factors appear to contribute more to risk (Bonta et al., 1998; Phillips et al., 2005). In this respect, there is an increasing amount of evidence to demonstrate that the risk of offending is enhanced by comorbidity with substance misuse (Short et al., 2013), and that "dual diagnosis" patients are significantly more violent than patients who suffer from either condition exclusively (Swanson et al., 1990). Comorbid patients have been found to use a greater frequency of violent behaviour; involving more victims and with the use of weapons (Phillips, 2000).

Comorbid patients spent less time in the community in comparison with those without a history of substance misuse (Derry and Batson, 2008). Substance misuse is also indicated to be related to an increased risk of criminal recidivism; hence many authors underlining the need for specific interventions, in both the health service and prison settings and in adolescent populations (Flynn et al., 2012).

Several authors indicate the lack of services, or current consensus on appropriate treatment interventions for patients whose mental illness is made more complex by substance misuse, both in and outside of secure hospital settings (McMahon et al., 2003; Lindqvist, 2007). Morris and Moore, (2009) put forward that identifying and meeting patients' needs in those with comorbid diagnoses should be addressed whilst in secure settings in order to minimise potential relapse once the patient has been discharged. Research into the needs of patients detained in high secure hospital settings in England reported that unmet needs for male patients were related to drug use in $23 \%$ of the sample 
and this was also the case for use of alcohol (Harty et al., 2004). Research has shown that treatment makes a significant, positive difference to certain attitudes towards substances, such as ambivalence (Morris and Moore, 2009).

A review of the relevant literature has indicated an established epidemiological link between substance misuse, mental illness and violent behaviour. The majority of studies have focused on relatively minor offending as the prevalence of serious offending is comparatively low (D'Silva and Ferriter, 2003). There remains a scarcity of information in relation to substance misuse in high secure hospital settings and no other studies have explored the differences between diagnoses in relation to SMU. This study aims to investigate the extent and severity of substance misuse (SMU) and corresponding treatment needs in patients with a primary diagnosis of personality disorder (PD) in comparison with mental illness (MI) in a high secure hospital.

\section{Method}

Participants

All patients $(n=240)$ detained in Broadmoor Hospital during a period of 10 months in 2011 were included in the study, which was carried out for the purpose of service evaluation. Predominantly, patients within this service are detained under the Mental Health Act (1983) and all are detained under conditions of high security for the highest level of risk associated with mental disorder. The vast majority of cases are held as a result of violent index offences. Referrals for transfer to Broadmoor Hospital may come from prisons or other secure hospitals. Patients detained in Broadmoor Hospital are allocated on admission to either the Personality Disorder Pathway or the Mental Illness Pathway, depending on their primary diagnosis. The high secure hospital is a unique environment in which patients have no access to drugs and alcohol while attempting to address their substance misuse treatment needs.

\section{Measures}

A Substance Misuse Screening Questionnaire was devised to gather all information required for this study. Items included substance type, history of past use and whether past use was harmful enough to meet the criteria for dependency using the International Classification of Diseases 10 (ICD-10).

\section{Procedure}

Prior to commencing, a proposal was sent for peer review to the West London Mental Health Trusts' 'Clinical Audit and Quality Initiatives' department for approval. Once approval had been received, information was gathered via the distribution of the Substance Misuse Screening Questionnaire. This 
was designed to record past SMU prevalence and its use in the context of offending and mental health as well as the assessment and treatment needs of patients. The patients' Responsible Clinicians (RC) were asked to record the relevant information over a 10 month period in 2011 . They received a copy of the questionnaire, within which the 'World Health Organisation' International Classification of Diseases 10 (ICD-10) criteria for harmful substance misuse and dependency syndrome was attached to assist them in making accurate selections. RCs were requested to indicate (by ticking the relevant boxes) whether or not their patients had a history of using specific substances and the extent of this past use. Substances included within the questionnaire comprised of alcohol, cannabis, solvents, heroin, cocaine/crack, ecstasy, amphetamine, tranquilisers (including benzodiazepines) and "other". For each, RCs were asked to indicate whether there was: 'no past use', 'past use', 'past harmful use' or 'past dependency'. They were also asked to indicate whether or not past substance misuse had contributed to their patients' index offences, past violence and onset of mental illness. They did this by circling one of the four following options: 'unlikely', 'probably', almost certainly' or 'not applicable'. Items relating to the exacerbation of mental illness symptoms were also included and whether or not the patient had engaged in treatment for SMU at Broadmoor Hospital. RCs were asked via the questionnaire whether the patient required any future treatment in relation to SMU and an item detailing any reports of excessive consumption of tea, coffee, carbonated drinks, water, food or PRN medications was incorporated.

All information gathered was stored in accordance with the Data Protection Act (1998) principles and within hospital information governance policies and procedures.

\section{Statistical Analysis}

Descriptive statistics were conducted to report the extent of substance misuse histories of the sample. Cross-tabulations and chi square analyses were conducted to explore the relationship between substance misuse and treatment status; mental disorder and offending behaviour. Means comparison analyses were carried out to investigate the length of hospital stay and the assessment and treatment of SMU. All data gathered was recorded and analysed using the Statistical Package for Social Sciences Version 17.0 (SPSS).

\section{Results}

Response Rate

A total of 240 questionnaires were sent out (corresponding to the total number of patients detained within Broadmoor Hospital during the study period). 230 questionnaires were returned; 
representing approximately $95 \%$ of the inpatient population. The hospital houses male patients exclusively and the sample therefore is representative of this.

\section{Table1- Description of Substances and Current Treatment Status}

\section{Descriptive Information}

The SMU data consists of 230 individual patient histories of substance misuse. ICD-10 statuses for the sample are provided in Table 2. Within the sample ( $n=230), 206$ (88.6\%) patients had a history of past substance misuse and $24(11.4 \%)$ had no evidence of past drug or alcohol use. The most common substances in relation to historical use were Alcohol and Cannabis of which $75 \%$ of the sample had a reported history of use. The ICD-10 status for past harmful use and past dependency for these substances was approximately $30 \%$ and $15 \%$ respectively.

There were no statistically significant differences indicated in the chi-square tests, when comparing the severity of past use of any substance across the ICD-10 diagnoses, and hence there was no difference in the frequencies of these levels. However, adjusted residuals for cell frequencies indicated that patients with a primary diagnosis of schizophrenia (adjusted residual=2.4) were more likely than patients with other diagnoses to have a history of SMU. Severity refers to the categories in Table 1. The severity was assessed using the Substance Misuse Screening Questionnaire.

Table 2 - Diagnosis and Severity of Substance Misuse (* includes schizotypal and delusional disorders)

\section{Categories of misused substances and treatment status}

Examining the status of SMU assessment across history of substance misuse, a significantly disproportionate number of patients with a past history of alcohol misuse had not been referred for a substance assessment. This would suggest that fewer people have been assessed for alcohol problems when compared to the number of referrals for assessment of drug use. Given the reported comorbid use of substances, no further substance specific statistical comparisons are made. However, when examining the SMU assessment for patients with a reported use of 'any drug', the trend is consistent. This is described in Table 1. 
Two hundred and six patients (88.6\%) had a history of substance misuse involving alcohol or drugs. The most common being alcohol and cannabis, which commonly overlapped in relation to past use with 143 patients (62.1\%) having a reported history of using both. 179 patients had a history of past use of at least one drug. A high prevalence of clinical and forensic risk factors were associated with SMU. In approximately two thirds of the sample, substances were linked with the onset of mental illness and the exacerbation of symptoms. A comparable number of patients also had a reported link between SMU and offending behaviour, including violence.

An assessment of SMU needs was under-representative in patients with a history of substance misuse; where approximately $60 \%$ of those with a history of SMU had not received a formal assessment to determine treatment needs. Patients with evidence of past histories for alcohol and any drug use were less likely to have received treatment ( $75.7 \%$ and $73.2 \%$ untreated respectively) and were also considered to have a higher treatment need (59.4\% and $67.3 \%$ - see Table 1.) Treatment need was notably high among patients (>70\%) where SMU was associated with clinical and forensic risk factors. This is detailed in Table 3.

When comparing the differences between PD and MI pathways, it was demonstrated that those with a diagnosis of MI (schizophrenia) are more likely to have used substances than those with a diagnosis of PD (93.3\% and $81.9 \%$ respectively). Furthermore, results indicate that patients with a diagnosis of $\mathrm{MI}$ are more likely to demonstrate a relationship between substance misuse and their index offence than those with a diagnosis of PD (74.3\% and $59.0 \%$ respectively). A similar relationship when exploring a link with violent behaviour was also found.

\section{Substance misuse and associated clinical and forensic problems}

Comparing future treatment needs for patients with evidence of clinical (mental health) and forensic (index offence and violence) risk factors linked with substance misuse showed a proportionally higher number of patients are identified as needing future SMU interventions. SMU as a risk factor for individual index offences was proportionally more common; either 'probably' or 'almost certainly' $(66.0 \%)$ than not, 'unlikely' (31.6\%). Additionally, this trend was consistent with a history of violent behaviour. Substance misuse was also more likely to be reported as a risk factor for both onset and exacerbation of mental illness compared with patients with an 'unlikely' association (Table 3).

Table 3 - Relationship of clinical variables to substance misuse history and treatment needs status (* where clinical variables are almost certainly linked to SMU) 


\section{Differences between diagnoses of Personality Disorder Vs Mental IIIness}

This study explored the differences between those patients with a primary diagnosis of personality disorder compared to mental illness (Table 4) A higher proportion of patients with a primary diagnosis of MI (Schizophrenia) had misused substances (93.3\% compared to $81.9 \%$ ). This was statistically significant $(X 2=6.552, d f=1, p=.01)$, and these patients were significantly more likely to be identified as needing SMU treatment whilst admitted to the hospital (64.3\% compared to $36.8 \%$ ), $(\mathrm{X} 2=12.534, \mathrm{df}=1, \mathrm{p}=.001)$. Therefore, patients in Broadmoor Hospital with a diagnosis of mental illness (consisting mostly of Schizophrenia as a primary diagnosis) were proportionally more likely to have used, and have a treatment need for substance misuse when compared with those with a primary diagnosis of personality disorder. However, this difference was not statistically significant $(x 2=3.497, d f=1, p=.061)$. The use of substances in the context of index offences was significantly more prevalent in patients with a diagnosis of $\mathrm{Ml}$ compared to those with $\mathrm{PD}(\mathrm{X} 2=4.748, \mathrm{df}=1$, $\mathrm{p}=.029)$.

\section{Table 4 - Comparison of past substance use, treatment status and clinical variables for patients in relation to a primary diagnosis of $\mathrm{MI}$ or PD}

\section{Length of stay in Broadmoor Hospital and substance misuse assessment and treatment}

When examining patients' length of stay and whether or not they had been referred for a SMU assessment whilst in the hospital, those patients with a longer period of admission were significantly more likely to have been referred for assessment than those earlier on in their admission. The mean ranks for those who were not referred $(n=140)$ was 100.84 . The mean ranks for those who were referred $(n=78)$ was $125.04(z-2.716 P$ value $<0.01)$. In terms of treatment, the mean ranks for those who were not treated $(n=171)$ was 101.15. The mean ranks for those who were treated $(n=49)$ was 143.11 ( $Z-4.068 \mathrm{P}$ value ,0.001).

\section{Discussion}

This study reports a cross-sectional survey of the prevalence of substance misuse and its link to clinical and criminogenic factors in a group of mentally disordered offenders, detained in a high 
secure hospital. The majority of the sample population had a primary diagnosis of mental illness (schizophrenia 64\%) and personality disorder (29\%) followed as the next prevalent diagnosis.

Response rate was very high, corresponding to $95 \%$ of the entire patient population of Broadmoor Hospital and within this, $88.6 \%$ of the sample had a history of substance misuse; alcohol and cannabis being the most common of substances used. At least one substance had been abused by $74.3 \%$ of the population and in two thirds of the sample, substance misuse was linked with the onset of mental health problems and symptom exacerbation, including violence. Patients who had a diagnosis of mental illness as compared with personality disorder were more likely to have used substances and to be in need of treatment to address this. In those with a diagnosis of schizophrenia, substance misuse was also more likely to be linked with violence and index offence. In accordance with previous research, results of this study indicate a high level of treatment need for patients with a history of substance misuse. Based on the reported associations between substance misuse and offending, and moreover encouraging outcomes of rehabilitation programmes which are associated with less time spent within secure settings (Derry and Batson, 2008); appropriate treatment could potentially lead to risk reduction and successful rehabilitation. The findings of this study highlight the importance of appropriate service provisions of psychological treatments for patients with substance related problems in high secure hospitals. Based on these results, there is reason to believe that a dedicated substance misuse service within Broadmoor Hospital could improve treatment delivery and prevent patients' returning without having received substance misuse treatment. It is however important to consider the potential limitations in implementing this in respect of the provision of resources for mental health services in the UK. Assessment and treatment of substance misuse could be significant in reducing recidivism following release, nevertheless abstinence within high secure psychiatric settings is enforced and therefore it may be important to evaluate treatment outcomes across settings, where access to substances may in fact increase. Durand et al., (2006) found that on-going substance misuse following admission to hospital was a common problem within forensic units. In addition, current literature in relation to the increased use of new psychoactive substances ('legal highs') highlight the difficulties in managing the impact of substance misuse. This would suggest treatment interventions focused on continuity of care and strengthening the links between secure services and drug and alcohol services could be significant in facilitating effective intervention.

An interesting finding in relation to this study, is regarding the difference between those who have a primary diagnosis of mental illness and those who have a primary diagnosis of personality disorder. Patients within the $\mathrm{Ml}$ pathway (who predominantly have a diagnosis of schizophrenia and associated symptoms) were more likely to have misused substances and to require treatment for 
this in comparison with those admitted into the PD pathway. When comparisons were made between these two groups in relation to clinical variables, it was found that patients with a diagnosis with mental illness were also more likely to have a link between substance misuse and index offence and violence. These findings would suggest that greater emphasis is placed on treating patients with a comorbidity of substance use and mental illness where resources may be limited.

The study's findings also indicate a closer relationship of substance misuse to schizophrenia than that of personality disorder. Moreover, the relationship between substance misuse and index offence appears to be more relevant for patients with a diagnosis of schizophrenia. This suggests that whilst in patients with a diagnosis of $P D$, violence and offending may be an intrinsic feature of their personality, in those with a diagnosis of schizophrenia, offending and violent behaviour is often mediated by substance misuse and possibly by impulsivity related to this. It could be hypothesized that substance misuse has a different nature according to the diagnosis; more 'occasional' and related to symptom relapse in patients with $\mathrm{MI}$ and therefore support the frequent reports of patients who 'self-medicate' by using illicit drugs and alcohol. This finding corroborates the existing literature identifying that substance misuse is a major factor in the risk of violence and aggression, and especially for those with a schizophrenia diagnosis (Soyka, 2000) and could be significant when considering risk assessment which is arguably a principal task in forensic mental health practice.

Interestingly, the study demonstrates that fewer patients have been assessed for problems related to alcohol than for drug related problems. This may reflect a clinical bias by clinicians who may consider drugs more of a concern or risk factor in relation to clinical and forensic variables.

Results of this study demonstrated a relationship between length of stay within services and assessment and treatment of substance misuse. Those with a longer period of admission were significantly more likely to have been referred for received treatment. This finding is not unsurprising, but given the high proportion of historical substance misuse, it could be argued that assessment and treatment for these needs should be a priority and take place sooner rather than later during an admission to hospital settings.

A strength of this study is the extremely high response rate which lends validity. A limitation exists in relation to the RCs potentially having had to refer to patients medical files, and reliance on selfreport data from patients. As all medical notes at Broadmoor Hospital at the time of the study was paper based, it is possible some information may have been missed. In addition, limitations in this study include the 'separation' of two pathways; mental illness and personality disorder. It could be argued that the two are not completely separate entities and in clinical practice, there is a more frequent overlapping of diagnosis. In line with the general population, the patient sample within this study may have comorbid disorders in Axis I and Axis II of the Diagnostic and Statistical Manual of 
Mental Disorder (DSM). However, for the purpose of this study, only the primary diagnosis at the period of data collection was considered in order to have a cross sectional picture of the correlation between substance misuse and the most prominent and relevant symptoms for a given mental disorder of the patients.

In conclusion, this study substantiates existing evidence that SMU contributes to mental health problems and criminogenic behaviour in the mentally disordered. Furthermore, the study reports new findings that characterize differences of the relationship of substance misuse to offending in schizophrenia and personality disorder in forensic psychiatric patients presenting to a high secure hospital. These findings have implications in meeting treatment needs of these patients, and in understanding of the link between substance misuse to offending in such patients. 
Implications for Practice

- The findings of this study could prove useful in practice regarding the relationship between substance use and risk of violence when considering the implementation of valid risk assessment. Despite the limitations of this study, it does establish a link between substance misuse and clinical and criminogenic factors.

- The study's findings that substance misuse may be linked more to violence histories and index offences in schizophrenia than in personality disorder, will assist in clinical risk assessments and care-planning.

- The study highlights the necessity of ensuring treatment for substance misuse, particularly for those with a diagnosis of Schizophrenia is made available.

- Dedicated services within Forensic settings would be desirable given the association between substance misuse and offending behaviour, however current resource provision would have to be taken into account and may be unrealistic in other settings.

- Further evaluations with a specific focus on treatment outcomes for this population would be beneficial.

- In assessing the effectiveness of interventions with this population, consideration should be given to access to substances in lesser secure environments and the increase in use of 'legal highs'. 


\author{
References \\ Bennett, D.J., Ogloff, J.R., Mullen, P.E., Thomas, S.D., Wallace, C and Short, T. (2011), "Schizophrenia \\ disorders, substance abuse and prior offending in a sequential series of 435 homicides, Acta \\ Psychiactrica Scandinavica, Vol. 124, pp. 226-33. \\ Bersani, G., Orlandi, V., Kotzalidis, G. D. and Pancheri, P. (2002), "Cannabis and Schizophrenia: \\ impact on onset, course, psychopathology and outcomes", European Archives of Psychiatry and \\ Clinical Neuroscience, Vol. 252, pp. 86-92.
}

Bobier, C and Warwick, M. (2005), "Factors associated with readmission to adolescent psychiatric care", Australian and New Zealand Journal of Psychiatry, Vol. 39, pp. 600-606.

Bonta, J., Law, M and Hanson, K. (1998), "The prediction of criminal and violent recidivisim among mentally disordered offenders: a meta analysis", Psychological Bulletin, Vol. 123 (2), pp. 123-142.

Derry, A. (2008), "The clinical response to substance use problems in forensic mental health services", The British Journal of Forensic Practice, Vol. 10(3), pp. 20-23.

Derry, A and Batson, A. (2008), "Getting out and staying out: does substance use treatment have an effect on outcome of mentally disordered offenders after discharge from medium secure service?", The British Journal of Forensic Practice, Vol. 10, pp. 13-17.

Doyle, M and Dolan M. (2006), "Predicting community violence from patients discharged from mental health services", British Journal of Psychiatry, Vol. 189, pp. 520-526.

D'Silva, K and Ferriter, M. (2003), "Substance use by the mentally disordered offenders committing serious offences- a high security hospital study", The Journal of Forensic Psychiatry and Psychology, Vol. 14 (1), pp. 178-193. 
Durand, M. A., Lelliott, P., Coyle, N. (2006), "Availiability of treatment for substance misuse in medium secure psychiatric care in England: a national survey", The Journal of Forensic Psychiatry and Psychology, Vol. 17, pp. 611-625.

Durbin, J., Lin, E., Layne, C and Teed, M. (2007), "Is readmission a valid indicator of the quality of inpatient psychiatric care?", Journal of Behavioural Health Services and Research, Vol. 34 (2), pp. 137-150.

Farrell, M., Howes, S., Taylor, C., Lewis, G., Jenkins, R., Bebbington, P., Jarvis, M., Brugha, T., Gill, B and Meltzer, H. (1998), "Substance misuse and psychiatric comorbidity: an overview of the OPCS National Psychiatric Morbidity Survey", Addictive Behaviours, Vol. 23 (6), pp. 909-918.

Flynn, D., Smith, D., Quirke, L., Monks, S and Kennedy, H.G. (2012), "Ultra high risk of psychosis on committal to a young offender prison: an unrecognised opportunity for early intervention", BMC Psychiatry, Vol. 12, pp. 100-113.

Gafoor, M and Rassool, G.H. (1998), "The coexistence of psychiatric disorders and substance misuse: working with dual diagnosis patients", Journal of Advanced Nursing, Vol. 27, pp. 497-502.

Gendel, M. H. (2006), "Substance misuse and substance related disorders in Forensic Psychiatry", Psychiatric Clinics of North America, Vol. 29(3), pp. 649-673.

Hall, W and Farrell, M. (1997), "Comorbidity of mental disorders with substance misuse", The British Journal of Psychiatry, Vol. 171, pp. 4-5.

Harty, M., Shaw, J., Thomas, S., Dolan, M., Davies, L., Thornicroft, G., Carlisle, J., Moreno, M., Leese, M., Appleby, L and Jones, P. (2004), "The security, clinical and social needs of patients in high security psychiatric hospitals in England", The Journal of Forensic Psychiatry and Psychology, Vol. 15 (2), pp. 208-221.

Isherwood, S and Brooke, D. (2001), "Prevalence and severity of substance misuse among referrals to a local forensic service", The Journal of Forensic Psychiatry, Vol. 12(2), pp. 446-454. 
Johnson, J.G., Cohen, P., Smailes, E., Kasen, S., Oldham, J. M., Skodol, A.E and Brooke, J. S. (2014), "Adolescent personality disorders associated with violence and criminal behaviour during adolescence and early adulthood", The American Journal of Psychiatry, Vol. 157(9), pp. 1406-1412.

Lindqvist, P. (2007), "Mental Disorder, substance misuse and violent behaviour: the Swedish experience of caring for the triply troubled", Criminal Behaviour and Mental Health, Vol. 17(4), pp. 242-249.

Lumsden, J., Hadfield, J., Littler, S and Howard, R. (2005), "The prevalence of early onset alcohol abuse in mentally disordered offenders", The Journal of Forensic Psyhicatry and Psychology, Vol. 16(4), pp. 651-659.

McGregor, K., Castle, D and Dolan, M. (2012), "Schizophrenia spectrum disorders, substance misuse and the four-facet model of psychopathy: the relationship to violence", Schizophrenia Research, Vol. 136, pp. $116-121$.

McMahon, C., Butwell, M and Taylor, P. J. (2003), "Changes in patterns of excessive alcohol consumption in 25 years of high security hospital admissions from England and Wales", Criminal Behaviour and Mental Health, Vol. 13(1), pp. 17-30.

Miller, F. T. and Tannenbaum, J. H. (1989), "Drug abuse in schizophrenia", Hospital Community Psychiatry, Vol. 40, pp. 847-849.

Moran, P and Hodgins, S. (2004), "The correlates of comorbid antisocial personality disorder in schizophrenia", Schizophrenia Bulletin, Vol 20(4), pp. 791-802.

Morris, C and Moore, E. (2009), "An evaluation of group-work as an intervention to reduce the impact of substance misuse for offender patients in a high security hospital", Journal of Forensic Psychiatry and Psychology, Vol. 20(4), pp. 559-576.

Mueser, K. T., Yarbold, P. R., Levinson, D. F., Singh, H., Bellack, A.S., Kee, K., Morrison, R.L. and Yaddam, K.G. (1990), "Prevalence of substance abuse in schizophrenia: demographic and clinical correlates", Schizophrenia Bulletin, Vol. 16(1), pp. 31-56. 
Mulvey, E. P., Shaw, E and Lidz, C.W. (1994), "Why use multiple sources in research on patient violence in the community?", Criminal Behaviour and Mental Health, Vol. 4(4), pp. 253-258.

Phillips, P. (2000), "Substance misuse, offending and mental illness: a review", Journal of Psychiatric and Mental Health Nursing, Vol. 7, pp. 483-489.

Phillips, H.K., Gray, N.S., MacCulloch, S.I., Taylor, J., Moore, S.C., Huckle, P and MacCulloch, M.J. (2005), "Risk assessment in offenders with mental disorders: relative efficacy of personal demographic, criminal history and clinical variables", Journal of Interpersonal Violence, Vol. 20(7), pp. 833-847.

Rasenen, P., Tuhonen, J., Isohanni, M., Rantakallio, P., Lehtonen, J amd Moring, J. (1998), "Schizophrenia, alcohol abuse and violent behaviour: a 26 year follow up study of an unselected birth cohort", Schizophrenia Bulletin, Vol. 24(3), pp. 437-441.

Scott, H., Johnson, S., Menezes, P., Thornicroft, G., Marshall, J., Bindman, J., Bebbington, P and Kuipers, E. (1998), "Substance misuse and risk of aggression and offending among the severely mentally ill", British Journal of Psychiatry, Vol. 172, pp. 345-350.

Serin, R.C. (1991), "Psychopathy and violence in criminals", Journal of Interpersonal Violence, Vol. 6(4), pp. 423-431.

Short, T., Thomas, S., Mullen, P and Ogloff, J.R. (2013), "Comparing violence in schizophrenia patients with and without comorbid substance use disorders to community controls", Acta Psychiactrica Scandinavica, Vol. 128(4), pp. 306-313.

Soyka, M. (2000), "Substance Misuse, psychiatric disorder and violent and disturbed behaviour", British Journal of Psychiatry, Vol. 176, pp. 345-350.

Steadman, H.J., Mulvey, E.P., Monahan, J., Robbins, P.C., Appelbaum, P.S., Grisso, T., Roth, L.H. and Silver, E. (1998), "Violence by people discharged from acute psychiatric inpatient facilities and by others in the same neighbourhoods", Arch Gen Psychiatry, Vol. 55(5), pp. 393-401. 
Steele, J., Darjee, R and Thomson, L.D. (2003), "Substance dependence and schizophrenia in patients with dangerous, violent and criminal propensities: a comparison of comorbid patients in a high security setting", Journal of Forensic Psychiatry and Psychology, Vol. 14(3), pp. 569-584.

Swanson, J.W., Holzer, C.E., Ganju, V.K. and Jono, R.T. (1990), "Violence and psychiatric disorder in the community: evidence from the epidemiologic catchment area surveys", Hospital and Community Psychiatry, Vol. 41(7), pp. 761-770.

Swinson, N., Flynn, S. M., While, D., Roscoe, A., Kapur, N., Appleby, L and Shaw, J. (2011), "Trends in rates of mental illness in homicide perpetrators", British Journal of Psychiatry, Vol. 198(6), pp. 485489.

Tavernor, R., Swinton, M., Collins, J., Brook, R and Beadle, A. (1998), "Return to special: an examination of the characteristics of patients who returned to Ashworth Special Hospital", Medicine, Science and the Law, Vol. 38(2), pp. 142-146.

Test, M.A., Wallisch, L.S., Allness, D.J. and Ripp, K. (1989), "Substance use in young adults with schizophrenia disorders", Schizophrenic Bulletin, Vol. 15(3), pp. 465-476.

Van Dongen, J., Buck, N and Van Marle, H. (2014), "Unravelling offending in schizophrenia: factors characterising subgroups of offenders", Criminal Behaviour and Mental Health, Vol. 25(2), pp. 88-98.

Vevera, J., Svarc, J., Grohmannova, K., Spilkova, J., Raboch, J., Cerny, M., Kalisova, L., Bartonkova, M., Bob, P and Susta, M. (2009), "An increase in substance misuse rather than other mental disorders has led to increased forensic treatment rates in the Czech Republic", European Psychiatry, Vol. 24(6), pp. 380-387.

Wallace, C., Mullen, P., Burgess, P., Palmer, S., Ruschena, D and Browne, C. (1998), "Serious criminal offending and mental disorder: a case linkage study", British Journal of Psychiatry, Vol. 172, pp. 477484. 
18

1

2

3

4

5

6

7

8

10

10

11

12

13

14

15

16

17

18

19

20

21

22

23

24

25

26

27

28

29

30

31

32

33

34

35

36

37

38

39

40

41

42

43

44

45

46

47

48

49

50

51

52

53

54

55

56

57

58

59

60 
Tables

Table 1 Description of Substances and Current Treatment Status

\begin{tabular}{|c|c|c|c|c|c|c|c|c|c|}
\hline \multirow[t]{2}{*}{ Substance } & \multicolumn{2}{|c|}{ Past use } & \multicolumn{2}{|c|}{$\begin{array}{l}\text { ICD-10 } \\
\text { Past } \\
\text { harmful }\end{array}$} & \multicolumn{2}{|c|}{$\begin{array}{c}\text { ICD-10 } \\
\text { Past } \\
\text { dependency }\end{array}$} & \multirow[t]{2}{*}{$\begin{array}{c}\% \\
\text { Assessed }\end{array}$} & \multirow[t]{2}{*}{$\begin{array}{c}\% \\
\text { Treated }\end{array}$} & \multirow[t]{2}{*}{$\begin{array}{c}\text { \% } \\
\text { Needing } \\
\text { RX }\end{array}$} \\
\hline & $\mathbf{N}$ & $\%$ & $\mathbf{N}$ & $\%$ & $\mathbf{N}$ & $\%$ & & & \\
\hline Alcohol & 177 & 77.0 & 64 & 27.8 & 32 & 13.9 & 39.3 & 24.3 & 59.4 \\
\hline Cannabis & 171 & 74.3 & 80 & 34.8 & 33 & 14.3 & 43.8 & 27.5 & 70.6 \\
\hline Solvents & 35 & 15.2 & 11 & 4.8 & 3 & 1.3 & 58.8 & 42.9 & 61.8 \\
\hline Heroin & 66 & 28.7 & 21 & 9.1 & 9 & 3.9 & 62.3 & 37.9 & 70.0 \\
\hline Cocaine / Crack & 104 & 45.2 & 31 & 13.5 & 10 & 4.3 & 52.6 & 32.7 & 71.1 \\
\hline Ecstasy & 70 & 30.4 & 19 & 8.3 & 4 & 1.7 & 57.6 & 37.1 & 71.4 \\
\hline Amphetamine & 75 & 32.6 & 24 & 10.4 & 7 & 3.0 & 45.7 & 28.0 & 61.8 \\
\hline Tranquilisers & 31 & 13.5 & 9 & 3.9 & 4 & 1.7 & 60.0 & 32.3 & 64.3 \\
\hline Others & 46 & 20.0 & 9 & 3.9 & 5 & 2.2 & 51.2 & 30.4 & 74.4 \\
\hline
\end{tabular}

Table 2 - Diagnosis and Severity of Substance Misuse (* includes schizotypal and delusional disorders)

\begin{tabular}{lllll}
\hline ICD10 Diagnosis & \%Sample & \% Past use & \multicolumn{2}{l}{ Severity of Past Use (\%) } \\
\cline { 4 - 5 } & & & Harmful & Dependency \\
Schizophrenia* & 63.5 & 93.2 & 54.1 & 25.3 \\
Mood disorders & 1.3 & 100 & 33.3 & 33.3 \\
Personality disorders & 28.7 & 81.8 & 47.0 & 27.3 \\
Developmental disorders & 1.3 & 100 & 66.7 & 0 \\
Not reported & 5.2 & 81.8 & 36.4 & 27.3 \\
\end{tabular}


Table 3 - Relationship of clinical variables to substance misuse history and treatment needs status (* where clinical variables are almost certainly linked to SMU)

\begin{tabular}{|c|c|c|c|c|c|}
\hline \multirow{2}{*}{$\begin{array}{l}\text { Clinical } \\
\text { Variables }\end{array}$} & \multicolumn{3}{|c|}{ Relationship with SMU (\%) } & \multicolumn{2}{|c|}{ Need for Treatment (\%)* } \\
\hline & 'Unlikely' & 'Probably' & $\begin{array}{l}\text { 'Almost } \\
\text { Certainly' }\end{array}$ & 'Yes' & 'No' \\
\hline Index Offence & 31.6 & 38.7 & 26.7 & 73.7 & 26.3 \\
\hline $\begin{array}{l}\text { Violent } \\
\text { behaviour }\end{array}$ & 28.4 & 43.1 & 28.0 & 71.7 & 28.3 \\
\hline MI onset & 38.4 & 42.9 & 12.9 & 85.2 & 14.8 \\
\hline $\begin{array}{l}\text { MI } \\
\text { exacerbation }\end{array}$ & 25.3 & 39.1 & 26.2 & 80.4 & 19.6 \\
\hline
\end{tabular}

Table 4 - Comparison of past substance use, treatment status and clinical variables for patients in relation to a primary diagnosis of MI or PD

$\begin{array}{lll} & \text { MI (\%) } & \text { PD (\%) } \\ \text { Past substance use } & 93.3 & 81.9 \\ \text { Referred for SMU Assessment } & 38.9 & 32.2 \\ & & \\ \text { Received SMU Rx } & 25.5 & 18.0 \\ \text { Requiring SMU Treatment } & 64.3 & 36.8 \\ & & \\ \text { Index Offence } & 74.3 & 59.0 \\ \text { Violent Behaviour } & 77.0 & 64.5\end{array}$

n.b. figures above exclude patients with no reported diagnosis. 